\title{
Evaluation of a College-Community Approach to Developing Multi-level Primary Health Care-Population Health Promotion Practicums for Nursing Students
}

\author{
Shari Laliberte \\ Bachelor of Science in Nursing Program, School of Health Sciences, Vancouver Community College, \\ slaliberte@vcc.ca
}

Zed Amarshi

Orthopedic Trauma, Fraser Health, zedamarshi@gmail.com

Rhonda Bennett

Vancouver Coastal Health, bennett.rhonda.l@gmail.com

Caroline Brunt

Licensed Practical Nursing Program, Bachelor of Science in Nursing program, School of Health Sciences, Vancouver Community College; B.C. Centre for Disease Control, cbrunt@vcc.ca

Katherine Fukuyama

Bachelor of Science in Nursing Program, School of Health Sciences, Vancouver Community College,

kfukuyama@vcc.ca

Nelly Gomez

Gender \& Sexual Health Initiative, BC Centre for Excellence in HIV/AIDS, nellynetwork@hotmail.com

\author{
Elaine Jones \\ Deborah Littman \\ Metro Vancouver Alliance, deborah.littman@gmail.com \\ Follow this and additional works at: https://qane-afi.casn.ca/journal
}

Bachelor of Science in Nursing Program, School of Health Sciences, Vancouver Community College; Indigenous Cultural Safety Training Program, Provincial Health Services Authority, eljones@vcc.ca

\author{
See nextpage for additional authors \\ Recommended Citation \\ Laliberte, Shari; Amarshi, Zed; Bennett, Rhonda; Brunt, Caroline; Fukuyama, Katherine; Gomez, Nelly; Jones, Elaine; \\ Littman, Deborah; McCarthy-Flynn, Michael; Martin, Maria; and Piebenga, Beverly (2017) "Evaluation of a College- \\ Community Approach to Developing Multi-level Primary Health Care-Population Health Promotion Practicums for \\ Nursing Students," Quality Advancement in Nursing Education - Avancées en formation infirmière: Vol. 3: Iss. 2, Article \\ 4. \\ DOI: https://doi.org/10.17483/2368-6669.1111
}

This Article is brought to you for free and open access by Quality Advancement in Nursing Education - Avancées en formation infirmière. It has been accepted for inclusion in Quality Advancement in Nursing Education - Avancées en formation infirmière by an authorized editor of Quality Advancement in Nursing Education - Avancées en formation infirmière. 


\section{Evaluation of a College-Community Approach to Developing Multi-level Primary Health Care-Population Health Promotion Practicums for Nursing Students}

\section{Cover Page Footnote}

Aligned with a participatory action research approach, we have listed our co-authors alphabetically to recognize the equal importance of our team members through their roles and engagement in our critical discussions and in co-creating the knowledge presented in this report (Greenwood, Brydon-Miller, \& Shafer, 2006). For a description of our process of preparing this manuscript, refer to the research methods section of this report. Address correspondence to: Shari Laliberte R.N. Ph.D. Faculty Member, Vancouver Community College at: slaliberte@vcc.ca Conformément à l'approche de recherche participative, nous avons dressé la liste de nos coauteurs par ordre alphabétique afin de reconnaître l'importance équivalente des membres de notre équipe et de leur participation aux discussions et à la création conjointe des connaissances présentées dans ce rapport (Greenwood, Brydon-Miller et Shafer, 2006). Pour une description du processus ayant servi d'inspiration pour la préparation de ce manuscrit, veuillez consulter la section de la méthode de recherche du présent rapport. Nous vous prions d'adresser toute correspondance à Shari Laliberte, inf. aut., Ph. D., membre du corps professoral, Vancouver Community College, à l'adresse slaliberte@vcc.ca.

\section{Authors}

Shari Laliberte, Zed Amarshi, Rhonda Bennett, Caroline Brunt, Katherine Fukuyama, Nelly Gomez, Elaine Jones, Deborah Littman, Michael McCarthy-Flynn, Maria Martin, and Beverly Piebenga 
An important objective of Canadian nursing degree programs is to educate students about the principles of primary health care (PHC) and population health promotion (PHP) (Canadian Association of Schools of Nursing, 2015). This mandate is challenged by the lack of full-scope PHP practice experiences within the Canadian health care system. Previous work has shown that most health promotion interventions occur at 1:1 and small group levels, with less attention to interventions that build supportive environments through healthy public policies (MacNeil, 2012). Within this context, it is challenging to find experienced mentors with a foundation in PHP skills beyond individual- and family-focused nursing care (Anderson, Richmond, \& Stanhope, 2004; Holt \& Warne, 2007; O’Brien-Larivee, 2011; Wade \& Hayes, 2010). Because of this challenge, nursing programs have turned to alternative, non-traditional, or non-health clinic service learning experiences (Cohen \& Gregory, 2009; Pijl-Zeiber \& Kalischuk, 2011; Reimer Kirkham, VanHofwegen, \& Harwood, 2005).

There are limited formal evaluations of alternative practicum experiences in nursing education programs. To address this need, faculty within a Bachelor of Science in Nursing (BSN) program at a Canadian urban college evaluated a fourth-year practicum in multi-level PHP practice. Student experiences spanned the PHP spectrum as outlined in models such as the Public Health Agency of Canada's Population Health Promotion Framework (Hamilton \& Bhatti, 1996) and the Ottawa Charter for Health Promotion (World Health Organization, Canadian Public Health Association, \& Health and Welfare Canada, 1986). Student projects aimed to apply PHC principles, with a key focus on inter-sectoral collaboration centered on both individual and family needs and addressing the social determinants of health (SDOH) across diverse populations. The purpose of this paper is to report the findings from a formal evaluation of this PHP practicum.

\section{Literature Review}

Alternative nursing practicum placements typically include a combination of service learning experience, theory, and practicum assignments. Students apply elements of the community health assessment process to a population, and they develop, implement, and evaluate a PHP initiative (e.g., Erickson, 2004; Kolomer, Quinn, \& Steele, 2010; Schoenfeld, 2003; Wade \& Hayes, 2010). In some cases, practicum instructors co-develop PHP projects and co-supervise students in partnership with community agencies (e.g., Anderson et al., 2004). A national survey of approaches to course objectives, conceptual approaches, and dimensions of community health nursing practicums reported a dominant focus on assessment objectives compared to action-oriented aspects of the PHP process (Cohen \& Gregory, 2009). A review of previous literature shows that there are a lack of placements that focus on policy development and advocacy.

\section{Reported Outcomes of Alternative Practicums}

Of the preliminary evaluation and anecdotal papers published, several positive outcomes have been reported for students and agency partners. Student outcomes include refining skills such as health education, developing new skills such as coalition building (Falk-Rafael, WardGriffin, Laforet-Fliesser, \& Beynon, 2004), developing health promotion plans in non-clinical environments (Erickson, 2004) with more confidence in PHP planning and program development skills, shared responsibility, accountability, and goal setting (Griffin, Williams, Hickman, Kirchner, \& Spitler, 2011). Developing deeper understanding, empathy, and a sense of social responsibility have been variously reported. This includes a greater awareness and empathy for 
how context and barriers impact health experiences (Bentley \& Ellison, 2005; Erikson, 2004), improved communication with vulnerable populations (Erikson), cultural awareness (Zandee, Bossenbroek, Friesen, Blech, \& Engbers, 2010), understanding personal biases and prejudices, and awareness about the relationship between social responsibility and professional practice (Bentley \& Ellison). Reimer Kirkham et al. (2005) observed the growth of critical awareness and sense of ownership in "needing to do something" to address issues that challenge people's health. Faculty also observed transformational learning whereby students have developed a broader "[conception] of nursing... igniting in them a passion to do more than render care to individuals in an institutional setting" (Redman \& Clark, 2002, p. 449). Previous literature also indicates a growth in student's independence, creativity, initiative, and critical thinking as a result of working within diverse community settings (e.g., Schoenfeld, 2003; Harwood, ReimerKirkham, Sawatzky, Terblanche, \& Van Hofwegen, 2009).

Community partners have also reported benefits. They have expressed appreciation for the completion of projects that would not be possible without the help of students (Falk-Rafael et al., 2004; Hunt, 2006). They reported increased organizational knowledge as a result of student research (Long et al., 2011) and increased awareness and knowledge regarding health among teachers, students, and their parents within school-based student projects (Schoenfeld, 2003). Within Anderson et al.'s (2004) partnership between a state health department and a school of nursing, students provided education regarding the core functions of public health to community health nurses and completed real-time community needs assessments, which directly assisted with the department's program planning.

\section{Gaps in Knowledge and Guiding Research Questions}

Although several positive outcomes have been reported within these practicum experiences, most of the literature is anecdotal, and there are limited formal evaluations that explore student and agency partner experiences. Furthermore, there is a lack of longitudinal follow-up with student alumni regarding the application of their learning to their nursing role. The participatory action research (PAR) team thus sought feedback from current and alumni students, faculty, and agency partners on their experiences of a fourth-year multi-level PHC/PHP practicum guided by the following research questions:

1. What outcomes did each partner experience as a result of participating within the PHP practicum?

2. What are the opportunities for further growth in how the practicum is administered in order to support current students and graduates from our program to apply principles of PHC/PHP in their nursing work?

\section{Description of Multi-Level Primary Health Care-Population Health Promotion Practicum}

Our PHC-PHP practicum engages students over two phases of the practicum. In the first phase, students take part in immunization training over a month. In the second phase, students work on PHC-PHP community projects for 12 hours per week over 10 weeks. Students apply concepts and theories from concurrent academic courses including population health promotion, health policy, health care ethics, health law, and core BSN curriculum concepts informed by a PHC perspective and a relational inquiry framework (Hartrick Doane \& Varcoe, 2015). The focus of this evaluation is the second phase of this practicum. 


\section{Team Member Roles}

Clinical faculty roles included: building partnerships with community groups and codeveloping a project focus; matching students to projects based on project needs, student experience, and career goals; coordinating orientation meetings and supporting the working relationship between students and agency mentors; and supporting students to apply theory and evidence, and explore the relevance of their project to nursing practice. Agency mentors helped students understand the target population, coached students on the project work, were role models, and introduced students to community partners. With coordination from faculty, mentors provided mid-term and final evaluation feedback that was included in student clinical evaluations. Students worked individually or in pairs. Each faculty member supervised 12-13 students.

\section{Full Spectrum Primary Health Care-Population Health Promotion Projects}

The goal of the practicum was to provide students with experiences that spanned the PHP spectrum. Projects ranged from individual and small group skill-building projects to community organizing and policy advocacy projects. Examples of skill-building projects were developing a free intercultural wellness program at a neighbourhood house and developing foot care educational materials for people who are homeless. Students also assessed community health needs to inform health promotion initiatives, assisted with the development of policy advocacy tools regarding environmental toxins, and helped create a digital storytelling project focused on renewing the federal health accord and funding of public health care.

\section{Clinical Seminars}

The goals of clinical seminars were to help students learn about full-scope, multi-level PHP practice and to reflect on PHP and PHC concepts in relation to their project. In the first month, there were weekly clinical seminars. After that, seminars were held every second week. Agency mentors gave guest lectures and shared how they applied PHP in their work. Guest lectures included stages of community organizing to address SDOH, application of a health equity lens to program and organizational development, gender transformative approaches to PHP practice, and coalition building in policy advocacy work.

\section{Practicum Course Assignments}

In phase two of the practicum, there were four assignments. In the first assignment, students developed an agency profile, identified the target population and/or key issue for their PHP project and collated statistical data to inform their project work. In the second assignment, students completed a college-community agency partnership agreement outlining project objectives, team member roles, and a timeline. The third assignment included a weekly progress report and clinical hours. Finally, students presented their work-including a critical reflection on their learning and implications for future nursing practice - to faculty, colleagues, and community mentors at a PHC World Café.

\section{Primary Health Care World Café}

In 2012, faculty and students organized and co-hosted a Primary Health Care World Café to conclude the practicum. The purpose of the World Café was to thank agency partners for their mentorship, support partner networking, and to engage in collective reflection on health trends and ways to advocate for health system transformation guided by a PHC model. At the World Café, each dialogue table focused on one of five PHC principles. Students gave a short 
presentation and took turns facilitating the dialogue. The insights were recorded and presented to the broader collective at the end of the World Cafe. ${ }^{1}$

\section{Research Methodology: Participatory Action Research and Evaluation}

Participatory action research (PAR) is a praxis-oriented, democratic, and collaborative approach to knowledge development in which research team members join an iterative cycle of action, reflection, and evaluation (McTaggart, 1991; Kelly, 2005; Stringer \& Genat, 2004). Research questions emerge from the day-to-day lives of the research team who work together to analyze key issues, envision solutions to those issues, and implement and evaluate solutions in an iterative way (Freire, 2006; Miskovic \& Hoop, 2006). According to Freire (2006), praxis is "reflection and action upon the world in order to transform it" (p. 28). This approach assumes that "local knowledge is rich and complex, that local stakeholders are experts in their own lives and situations, and that knowledge... is co-generated through collaborative effort" (Greenwood, Brydon-Miller, \& Shafer, 2006, p. 83).

For this practicum evaluation, research was change oriented, and we engaged key partners to reflect on the practicum to make improvements that would benefit students and agency partners. This approach applies principles of transparency, collaboration, participation, and democracy with key stakeholders who are engaged as co-researchers within the design, implementation and analysis data in of the inquiry process (Mercado-Martinez, Tejada-Tayabas, \& Springett,, 2008). Emergent approaches draw on both quantitative and qualitative methods to evaluate aspects of a program that are relevant to the various stakeholders (Mercado-Martinez et al.).

The evaluation plan and research process was developed and facilitated by a faculty member who also taught this practicum. The college research ethics review board approved the research proposal in May 2013.

\section{Recruitment and Informed Consent Process}

The research facilitator, who was one of the practicum instructors, provided an overview of the research-evaluation project to practicum students including participant rights, the right to not participate in the project, and the right to withdraw at any point without negative outcome. Participants were informed of the benefits and risks of participating in this study including concerns about the risk of distress if they shared feedback that might distress their faculty member and/or community mentor. One week prior to data collection, all research participants, including alumni students and agency partners, received an email invitation and copy of the informed consent.

\section{Research Participants}

A total of 26 fourth-year students, three faculty, 16 agency partners, and 105 alumni students were invited to participate. Research participants who engaged in the group-based feedback sessions included one faculty, five agency mentors, 19 students, and one alumnus who had completed one year of nursing practice. Four students, two faculty members, two agency

\footnotetext{
${ }^{1}$ For a more detailed elaboration on this process, refer to The Canadian Association of Schools of Nursing Public Health Teaching Strategies website: http://publichealth.casn.ca/ that showcased this approach to teaching PHP.
} 
partners, and two alumni completed the online survey. The total sample of research participants included 36 participants out of a total of 150 for a response rate of $24 \% .^{2}$

\section{Data Collection and Analysis}

In order to prevent coercion in the recruitment and preserve the voluntary consent process, participants had two options (Ferguson, Yonge, \& Myrick 2004). They could take part in a 20-minute group-based research-evaluation dialogue discussion held during the World Café or they could complete an anonymous online survey, or both. The anonymous option was offered to ensure that students had a way to share their feedback if they were not comfortable doing so with faculty or community members in a public setting. By situating part of the data collection process within the World Café, students and faculty/community agencies had free choice regarding which dialogue table to attend. We assumed this prevented participants from feeling pressured to participate in the evaluation dialogue table because they had the option to share their feedback via the anonymous survey, or not to participate without faculty awareness. Final course evaluations were completed prior to the World Café to further minimize coercion.

Four third-year nursing students assisted with a literature review and were engaged as coinvestigators to obtain informed consents and collect data in exchange for course credit within their nursing research course. These students received a two-hour training session, follow-up email guidance, and an overview of the informed consent and data collection process. Students received handouts about dialogue session guidelines, including semi-structured questions. The research facilitator, who oversaw the World Café, was available to answer questions from student co-investigators as they engaged research participants in the informed consent and data collection process. Discussions were audio-recorded and professionally transcribed to support data analysis. Online survey forms were downloaded and integrated within the main transcript.

To support a thematic analysis of the evaluation data, all identifying information for dialogue session participants was removed by the research facilitator; participant responses from table discussions and online surveys were organized within the main research questions. Three third-year nursing students were offered an overview of qualitative data collection methods and a one-hour follow-up training session on thematic data analysis by the research facilitator. These students assisted with the preliminary thematic analysis in exchange for course credit in their research course. The research facilitator re-analyzed the data, comparing her analysis to the student's analysis to develop the main themes. A preliminary draft of this paper was shared with the PAR team who offered critical reflections on the themes. Additional insights from this feedback process are included within the findings presented in this report.

Team members reviewed and provided feedback on four drafts of this paper, which was written by the research facilitator. Two other members assisted in reviewing and summarizing findings from recent literature to support the preparation of the final draft of this report. All team members approved the final draft of this report.

\footnotetext{
${ }^{2}$ Note that this may not reflect the exact sample size if participants engaged in both the group interviews and the online survey.
} 


\section{Findings}

\section{Reported Outcomes for Team Members}

Faculty, students, and agency partners reported a variety of outcomes from having participated within this practicum.

\section{Current Students}

Students reported three main areas of learning including: deeper critical awareness regarding the context of health and healing experiences, greater understanding of the nature of PHP practice, and their leadership role with a key focus on cultivating self-initiative.

Growing critical awareness regarding the context of health and healing. Similar to previous work (Bentley \& Ellison, 2005; Erickson, 2004; Reimer Kirkham et al., 2005; Zandee et al., 2010), students reported gaining empathy for people's life situations and health experiences including a better understanding of the challenges that people face in accessing health care services. One student shared: "the practicum opened my eyes about the complexity of people`s life situations, struggles, system barriers, and health issues." Students shared how they "[took] the role of the patient...being able to walk that role... [getting a sense] of how people feel," and they gained a deeper appreciation for the need to address barriers that people face in accessing health services, such as poverty, past trauma, and the need to engage in various survival activities.

While students expressed appreciation for their expanded awareness, their responses also indicated an experience of "dissonance" within their growing "critical awareness" (Reimer Kirkham et al., 2005). Students reported feeling sadness and anger when witnessing the difficult life circumstances that some people face. They expressed mixed feelings about working as a nurse in a context of resource constraints and not being able to engage in best practice. One current student shared, “I don't want to be a nurse. I don't want to do any job where tools and resources are actively held due to poor political decisions thus preventing me from achieving excellence in my field. What's the point?"

Learning about the nature of multi-level PHP practice. Students reported learning about the stages of a PHP project and the nature of community development and policy advocacy work. This included a greater appreciation for how the SDOH affect people's lives and a growing awareness of the importance of policy advocacy and collaboration to address the SDOH. Several students described developing a "greater understanding of where nurses can advocate in large and small scale ways" (current student). Students gave examples of how to address low-wage poverty including promoting living wage bylaws and addressing environmental toxins through consumer protection policies.

Students highlighted the differing time dimension of community organizing and policy advocacy work and the importance of cultivating patience. One current student expressed frustration at not seeing the immediate results of her policy advocacy work and explained how she coached herself through this frustration: "you may not see immediate results now, but it's a long term, larger picture, and remembering that."

Students reported learning about the importance of collaboration and the PHC principle of public participation to PHP practice. Students expressed the importance of coalition building, inter-sectoral collaboration, and community organizing to address the SDOH. Students reported learning about the importance of creating links between organizations to build community 
capacity and increase access to health services, for example, bringing a smoking cessation preventative health program into a housing program for people living on a low income. Students also reported an increased appreciation of ways to seek client participation and evaluation feedback for program and policy development in both acute and community health settings. One student shared, "I find this process absolutely fabulous when we involve the general public or people who are passionate about a certain policy or change that they want to see." As part of their growing awareness of working at broader systems levels, students also reported learning about the use of social media in health education marketing campaigns and coalition building.

Development of leadership. Similar to previous findings (Erickson, 2004; Harwood et al., 2009; Long et al., 2011; Schoenfeld, 2003), students reported growth in their "leadership and self-initiative." The opportunity for self-initiative was the most commonly identified strength of the practicum. Students expressed appreciation for the flexible, autonomous, and creative nature of the practicum in a context of supportive mentor-faculty-peer relationships. Regular communication with the faculty member and agency mentor was an important part of creating this supportive learning environment.

\section{Alumni Students}

Similar to current students, alumni students reported a shift in understanding "individually based care to community level care", and they applied learned skills such as "communication, collaboration, self-autonomy, and leadership" to their work. They also noted the importance of using research to guide practice. They reported greater awareness of the SDOH and the reasons for health inequities between population groups, which supported them in conducting "comprehensive" assessments in their nursing practice. Alumni expressed the importance of collaboration and the need to work from the "bottom up" in both the acute and community setting. Alumni highlighted the importance of research skills to inform PHP work and the interrelation with collaborative practice. A recent graduate emphasized how PHP requires a "new kind of knowledge for a different kind of nursing." Another alumnus reminisced about her project with an immigrant group and the importance of exploring the community's need and "just digging for more information, and sorting through research... to come up with something that would meet their identified problem."

Likely because of their practicum and front-line nursing practice, alumni highlighted their awareness of the importance of a strong connection between the "spheres of acute care and community... because when patients get out of the hospital they're back into the community and they are going through the same problems and they'll be ending up in the hospital again."

\section{Agency Partners}

Agency partners identified two main benefits of collaborating with students and faculty. Aligned with previous findings (Falk-Rafael et al., 2004), several partners expressed appreciation for student work on projects that they likely would be unable to complete due to funding challenges and resource constraints. Similar to previous work that reported on how students bring fresh perspectives to the agency (Reimer-Kirkham, Terblanch, Sawatsky, \& Eriksen, 2016), partners also described experiencing growth and learning themselves, such as learning new ways to engage culturally diverse groups in community organizing. 


\section{Feedback on the Administration of the Practicum}

Participants were invited to identify strengths and areas of growth within this practicum. The feedback focused on the process of setting up and assigning students to PHC-PHP projects, the roles of team members, the timing of the student projects within multi-year PHP projects, linking theory and practice within seminars and academic courses, and building collaborative partnerships. An additional theme that emerged included the importance of ensuring the sustainable impact of student project work in the community setting.

\section{Process of Developing and Assigning Students to PHC-PHP Projects}

Participants recognized the challenges and benefits associated with faculty- versus student-developed projects. Benefits of student-developed projects included the opportunity to work within their areas of interest to support their future career goals and to provide "a sense of pride and ownership." One agency partner noted that a drawback to student-developed projects was insufficient time (10 weeks) for students to research and develop an effective project. She also noted that students tend to "stay within their 'comfort zone' of charitable/service-based projects, and are unlikely to take on something 'alien' like community organizing." This feedback aligned with some students who shared that they discovered new areas of nursing practice that they would not have considered prior to this practicum. Drawbacks to the facultydriven approach include the amount of time required to engage with community partners in order to explore mutual needs and to assign students to projects and how faculty-developed projects may not provide experiences that align with student interests. Benefits include the opportunity to build partnerships with agency partners in ways that align with faculty members' expertise and developing longer-term projects and partnerships between the BSN program and community partners.

\section{Roles of Team Members}

Both students and agency mentors appreciated that faculty were available to coordinate practicum orientation, consult about course learning objectives, support students to apply theory to practice - including coordinating guest lectures - share information and examples of theory application, and facilitate problem solving and communication between the student and agency mentor. Students also appreciated that faculty normalized the nature of PHP practice and helped them apply elements of PHP/PHC practice. Students appreciated mentors' expertise and when they provided timely feedback, were flexible, and connected students to community groups to support their project work. Students also expressed appreciation for the agency mentor's guidance regarding broader level PHP work, such as policy advocacy, to help students anticipate outcomes and be strategic.

Students expressed appreciation when faculty and mentors functioned as background support. They appreciated the freedom and opportunities for developing leadership, selfinitiative, and creativity. Along with other students, one student expressed her appreciation for the "really supportive environment... and the freedom to take control and plan my own project while having the support there that I needed if I needed it" (current student).

\section{Interrelated Role of Faculty and Agency Mentor}

Faculty emphasized the importance of negotiating the supervisory role of faculty and agency mentors to ensure that students have an adequate level of supervision. Addressing Reimer-Kirkham et al.'s (2016) finding that incongruities can exist between faculty and partner 
expectations, thus creating tensions in the relationship, faculty emphasized the importance of negotiating the roles of faculty and mentor to ensure a healthy working relationship and that students get consistent feedback. Agency mentors and students appreciated the consultant role that faculty took to inform theory and evidence-based practice. Some mentors appreciated having faculty available to consult on their own projects: "The faculty were very helpful...when we were developing programs, the instructor was very able to give examples and tie it back to the course work so that it wasn't something new and daunting and scary" (agency partner).

Similar to Harwood et al.'s (2009) survey, which found that direct nurse educator supervision on PHP work depended on student and agency factors, faculty noted that their role varied depending on the nature of the project, mentor availability, and the level of student knowledge, skills, and strengths.

\section{Timing of Student Projects within Multi-year PHP Projects}

Faculty and mentors emphasized the need to identify a project that students can complete within the 10-week practicum to enable quality work and to give students a sense of completion and achievement. Aligned with Cohen and Gregory's (2009) recommendation that two terms of population-based community clinical health exposure is the "gold standard" to enable students time to integrate knowledge and skills, students and faculty recommended expanding the focus of the subsequent preceptorship so that students could continue to work on their project beyond the PHP practicum and model the expansion of nurses' scope of practice to include PHP work.

\section{Ensuring the Sustainable Impact of Student Project Work in the Community Setting}

An interrelated concern raised by several students and agency partners focused on the sustainability of student project work. Students worried that their project work would not be carried on when they finished their practicum. Similar to an increase in numbers of nursing students who indicated an intention to volunteer after their service learning experience (Bentley \& Ellison, 2005), a few students wondered how they could continue to work on the projects in a volunteer capacity, but they also anticipated they wouldn't have time once they began their final preceptorship. Some students coached themselves to let go with the hope that others would carry on their project work. The importance of building in a sustainability plan in the project development phase was recognized.

\section{Linking Theory with Practice across Seminars and Academic Courses}

Students raised the need for greater support to link theory with practice. Students recommended having more alumni and/or an acute-community liaison nurse to share how they apply theory to practice. Students also recommended more seminar time, especially toward the end of the term, to better support learning on how to apply theory to practice. One student shared: "right when our projects were getting interesting, we didn't get a chance to share about it anymore."

Faculty and students also recommended the need for more hands-on tools and resources to prepare students for project work. One faculty explained how she was developing a resource library, including guides to running a focus group, survey development, and analyzing needs assessment data. Faculty also provided opportunities for students to practice their new skills in seminars by inviting students to pilot their PHP work with peers, such as trialing needs assessment tools, health surveys, and conducting focus groups. 


\section{Building Collaborative Partnerships}

A strength of this practicum was building partnerships with community agencies. Agency partners expressed support for the multi-level PHP projects and emphasized the importance of seeking non-traditional health placements so students learn about the work of other disciplines and community groups. This was identified as an important foundation for encouraging nursing graduates to engage with diverse partners in their nursing practice. Similar to other work (FalkRaphael et al., 2004), finding common ground between agency needs and student learning needs was important for developing long-term partnerships between the BSN program and community agencies. One partner recommended that the main way to foster long-term partnerships is to "look at developing more strategic relationships that concentrate on longer-term projects than the timescale of the relatively short placements." The World Café was a useful forum for strengthening partnerships among faculty, students, alumni, and agency partners. Students shared that the World Café enabled them to see their growth in this practicum and to celebrate their work with project partners. Agency partners expressed appreciation for a chance to network with other agencies. Faculty shared how new project ideas for future student practicums emerged from the discussions.

\section{Discussion}

Findings from this study support the importance of continuing to develop alternative practicum experiences to support nursing students in developing competencies in PHP practice in the community setting and acute care setting. Alumni student feedback reported that this experience helped them appreciate the broader context of health and deepen their understanding of the reasons for health inequities between population groups, which in turn strengthened their commitment to comprehensive assessments that consider the SDOH. They also shared how they learned about the importance of evidence and drawing on diverse data to understand the broader health trends of various population groups, including the importance of working collaboratively and building bridges between acute and community settings to prevent re-hospitalization due to unaddressed SDOH. Alumni reported applying their learning about collaboration, autonomous nursing practice, leadership, and evidence-based practice within their acute care nursing practice. Their feedback was further supported by agency partners who emphasized the importance of seeking non-traditional health placements so students can learn about the work of other disciplines and community groups. This was identified as an important foundation for encouraging nursing graduates to engage with diverse partners in their nursing practice.

While we agree that alternative placements may not fully address the theory-practice gaps in community health nursing $(\mathrm{CHN})$ practice and in ensuring that students develop foundational competencies in CHN practice (Pijl-Zieber, Barton, Awosoga \& Konkin, 2015), these findings suggest that a strong faculty role and guest lectures from nurses who apply PHP to their nursing practice can help students to connect their experiences in alternative placements to $\mathrm{PHP} / \mathrm{PHC}$ concepts and theories. While more research is needed, this experience suggests that projects that span the spectrum of PHP, combined with student seminars, offer an opportunity to raise student awareness of the multiple level skills and abilities that nurses require, both in CHN practice and acute care. Arguably this approach to learning is equivalent to traditional health care placements where budgetary cutbacks and broader austerity measures limit the scope of nursing, which in turn, limits students' ability to learn equally important PHP skills such as policy advocacy and community organizing skills that address the SDOH. The World Café also addresses the call to engage in advocacy for health system transformation guided by a PHC model (Pijl-Zieber \& 
Kalischuk, 2011). For example, discussions have generated ideas such as the use of documentary film to explore student experiences as they transition from our practicum into nursing practice. The documentary could raise public awareness about the need for expanded scopes of nursing practice.

Similar to previous evaluations and anecdotal reports, students reported learning in three main areas: a deeper critical awareness about the context of health, a greater understanding of multi-level PHP practice, and the development of leadership skills and self-initiative. A central outcome of student participation was their commitment to addressing contextual factors that affect health outcomes. This was evident in student reflections that highlighted the importance of policy advocacy work in addressing the SDOH, and their concerns about the sustainable impact of their project work, and how to continue the project work when the practicum ended.

These findings emphasize the importance of engaging diverse population groups (e.g., Falk-Rafael et al., 2004) and inter-sectoral groups (Institute of Medicine, 2016) in the development of PHP practicums, as well as the importance of developing projects that promote health at the structural level to educate students about multi-level PHP practice. Students who had these experiences described learning about the nature of hospital nursing compared to community organizing and policy advocacy work. Similar to previous work (Anderson et al., 2004; O'Brien-Larivee, 2011), students gained insight into the nature of policy advocacy work including the need for strategic policy planning in response to the political landscape, the policy process, and the roles nurses play in advocating for changes in social and environmental conditions that promote health.

These findings extend the roles that Falk-Rafael et al. (2004) outline for faculty and agency partners where faculty are primarily focused on helping students link theory to practice while the agency partners focus on coaching the student. In addressing discrepant expectations between agency partners and faculty (Reimer-Kirkham et al., 2016), these findings emphasize the interrelated role of the faculty and agency partner in supervising students. It is important to negotiate this supervisory role at the beginning of the practicum in order to enable adequate supervision and healthy working relationships, and it allows faculty to plan workload while cultivating longer-term partnerships with agencies.

These findings also suggest the importance of developing projects that meet community needs in ways that are sustainable and support partnerships. Students expressed a genuine caring for the outcomes of their work with the communities they served. Some considered ways they could continue their project work on a longer-term basis. In terms of ensuring the sustainability of student project work, the team members made a few recommendations including: the need for a sustainability plan and funding to enable agencies to continue the students' work, organizing practicums to enable project work to continue across student cohorts, and changing nursing curricula to enable students to work on their PHP projects in their final preceptorship (which follows their PHP practicum). Faculty felt this would model the full scope of nursing practice and serve as an important platform for advocacy oriented to expanding the scope of nursing practice.

Overall, findings from this evaluation support previous work that emphasized the importance of mutually beneficial, well-established partnerships that address student learning and agency partner needs. As well, ongoing faculty presence and processes that support student initiatives and clear course objectives help students to link theory with practice (Harwood et al., 
2009). These findings also align with models that highlight the importance of developing intersectoral and experiential opportunities to support critical thinking and lifelong learning that is attentive to the "value of relationships and collaborations for understanding and addressing community-identified needs and strengthening community assets" (Institute of Medicine, 2016).

There are two key limitations in this evaluation. First, student reports of learning were relied on, which may not coincide with their actual academic achievement. Also, student reflections were collated within a thematic analysis to document the main learning outcomes of this practicum. Thus, there is the potential of varied levels of knowledge and skill development for each student as a result of their participation in this practicum. Future research could include a comparison of qualitative data exploring students' lived experiences as well as their achievement in their academic and practicum course assignments. Second, there was a limited response rate from alumni. Therefore, it is important to find ways to better engage alumni nurses in future research in order to better track the long-term outcomes of these practicums for graduates of BSN nursing programs.

\section{Conclusion}

The evaluation of a PHP practicum within an urban context identified several benefits among partners. Current students reported three main areas of learning, including a deeper critical awareness of the context of health experiences, a greater understanding of multi-level PHP practice, and leadership and self-initiative. Importantly, this included a deeper understanding of community organizing and policy advocacy oriented to promoting healthy public policy. Key elements of the administration of this practicum were highlighted as effective in supporting long-term partnerships with inter-sectoral partners and in promoting student learning. Findings from this evaluation emphasize the importance of developing projects that span the full scope of PHP practice. Importantly, these practicums need to include some community organizing and policy advocacy focused projects to support student learning about multi-level PHP practice. 


\section{References}

Anderson, D. G., Richmond, C., \& Stanhope, M. (2004). Enhanced undergraduate public health nursing experience A collaborative experience with the Kentucky Department for Health. Family Community Health, 27(4), 291-297. https://doi.org/10.1097/00003727-20041000000005

Bentley, R., \& Ellison, K. J. (2005). Impact of a service learning project on nursing students. Nursing Education Perspectives, 26(5), 287-290.

Canadian Association of Schools of Nursing. (2015). National Nursing Education Framework Final Report. Ottawa, ON: Author.

Cohen, B., \& Gregory, d. (2009). Community health clinical education in Canada: Part 1 "State of the art". International Journal of Nursing Education Scholarship, 6(1), 1-17. https://doi.org/10.2202/1548-923x.1637

Erickson, G. P. (2004). Community health nursing in a nonclinical setting Service-learning outcomes of undergraduate students and clients. Nurse Educator, 29(2), 54-57. https://doi.org/10.1097/00006223-200403000-00005

Falk-Rafael, A. R. F., Ward-Griffin, C., Laforet-Fliesser, Y., \& Beynon, C. (2004). Teaching nursing students to promote the health of communities A partnership approach. Nurse Educator, 29(2), 63-67. https://doi.org/10.1097/00006223-200403000-00007

Ferguson, L. M., Yonge, O., \& Myrick, F. (2004). Students' involvement in faculty research: Ethical and methodological issues. International Journal of Qualitative Methods, 3(4), 5668. https://doi.org/10.1177/160940690400300405

Freire, P. (2006). Pedagogy of the oppressed (M. B. Ramos, Trans., 30th ed.). New York, NY: Continuum.

Greenwood, D. J., Brydon-Miller, M., \& Shafer, C. (2006). Intellectual property and action research. Action Research, 4(1), 81-95. doi:10.1177/1476750306060581

Griffin, S. F., Williams, J. E., Hickman, P. B., Kirchner, A. B., \& Spitler, H. (2011). A university, community coalition, and town partnership to promote walking. Journal of Public Health Management and Practice, 17(4), 358-362. https://doi.org/10.1097/phh.0b013e318221471c

Hamilton, N., \& Bhatti, T. (1996). Population health promotion: An integrated model of population health and health promotion. Retrieved from: http://www.phac-aspc.gc.ca/phsp/php-psp/index-eng.php

Hartrick Doane, G., \& Varcoe, C. (2015). How to nurse Relational inquiry with individuals and families in changing health and health care contexts. New York, NY: Wolters Kluwer Lippincott Williams \& Wilkins.

Harwood, C. H., Reimer-Kirkham, S., Sawatzky, R., Terblanche, L., \& Van Hofwegen, L. (2009). Innovation in community clinical placements: A Canadian survey. International Journal of Nursing Education Scholarship, 6(1), 1-19. https://doi.org/10.2202/1548923x.1860 
Holt, M., \& Warne, T. (2007). The educational and practice tensions in preparing pre-registration nurses to become future health promoters: A small scale explorative study. Nurse Education in Practice, 7, 373-380. https://doi.org/10.1016/j.nepr.2006.11.009

Hunt, S. (2006). A practice placement education model based upon a Primary Health Care perspective used in South Australia. British Journal of Occupational Therapy, 69(2), 8185. https://doi.org/10.1177/030802260606900206

Institute of Medicine. (2016). A framework for educating health professionals to address the social determinants of health. Retrieved from: https://www.nap.edu/catalog/21923/aframework-for-educating-health-professionals-to-address-the-social-determinants-of-health

Kolomer, S., Quinn, M. E., \& Steele, K. (2010). Interdisciplinary health fairs for older adults and the value of interprofessional service learning. Journal of Community Practice, 18(2-3), 267-279. https://doi.org/10.1080/10705422.2010.485863

Long, J. A., Lee, R., Frederico, S., Battaglia, C., Wong, S., \& Earnest, M. (2011). Developing leadership and advocacy skills in medical students through service learning. Journal of Public Health Management Practice, 17(4), 369-372. https://doi.org/10.1097/phh.0b013e3182140c47

MacNeil, A. (2012). Exploring action on the social determinants of health in Canada's health regions. (Master's Thesis, University of Victoria, Victoria, BC). Retrieved from: https://dspace.library.uvic.ca:8443/handle/1828/4409

McTaggart, R. (1991). Principles for participatory action research. Adult Education Quarterly, 41(3), 168-187. https://doi.org/10.1177/0001848191041003003

Mercado-Martinez, F. J., Tejada-Tayabas, L. M., \& Springett, J. (2008). Methodological issues in emergent evaluations of health programs: Lessons from Iberoamerica. Qualitative Health Research, 18(9), 1277-1288. https://doi.org/10.1177/1049732308321755

Miskovic, M., \& Hoop, K. (2006). Action research meets critical pedagogy. Qualitative Inquiry, 12(2), 269-291. https://doi.org/10.1177/1077800405284367

O'Brien-Larivee, C. (2011). A service-learning experience to teach baccalaureate nursing students about health policy. Journal of Nursing Education, 50(6), 332-336. https://doi.org/10.3928/01484834-20110317-02

Pijl-Zieber, E. M., Barton, S., Awosoga, O., \& Konkin, J. (2015). Disconnects in pedagogy and practice in community health nursing clinical experiences: Qualitative findings of a mixed method study. Nurse Education Today, 35(10), e43-e48.

https://doi.org/10.1016/j.nedt.2015.08.012

Pijl-Zeiber, E. M., \& Kalischuk, R. G. (2011). Community health nursing practice education: Preparing the next generation. International Journal of Nursing Education Scholarship, 8(1), 1-13. https://doi.org/10.2202/1548-923x.2250

Redman, R., \& Clark, L. (2002). Service-learning as a model for integrating social justice in the nursing curriculum. The Journal of Nursing Education, 41(10), 446-449.

Reimer-Kirkham, S., Terblanche, L., Sawatzky, R., \& Eriksen, C. H. (2016). Host agency perspectives on facilitating community-based clinical experiences for nursing students. 
Quality Advancement in Nursing Education, 2(1), 1-14. https://doi.org/10.17483/23686669.1048

Reimer Kirkham, S., VanHofwegen, L., \& Harwood, C.H. (2005). Narratives of social justice: Learning in innovative clinical settings. International Journal of Nursing Education Scholarship, 2. doi:10.2202/1548-923x.1166

Schoenfeld, B. M. (2003). A school nursing practicum at the University of Saskatchewan, Canada. Journal of School Health, 73(7), 281-283. https://doi.org/10.1111/j.17461561.2003.tb06580.x

Stringer, E., \& Genat, W. J. (2004). Action research in health. Upper Saddle River, NJ: Pearson.

Wade, G. H., \& Hayes, E. (2010). Challenges and opportunities associated with preceptored community health clinical experiences. Public Health Nursing, 27(5), 459-467. https://doi.org/10.1111/j.1525-1446.2010.00879.x

World Health Organization, Canadian Public Health Association, \& Health and Welfare Canada. (1986, November). Ottawa Charter for Health Promotion. Presented at the First International Conference on Health Promotion, Ottawa, ON.

Zandee, G., Bossenbroek, D., Friesen, M., Blech, K., \& Engbers, R. (2010). Effectiveness of community health worker/nursing student teams as a strategy for public health nursing education. Public Health Nursing, 27(3), 277-284. https://doi.org/10.1111/j.15251446.2010.00854.x 